\title{
PUBLISHER CORRECTION \\ Correction to: Necessary Optimality Conditions for Optimal Control Problems in Wasserstein Spaces
}

\section{Benoît Bonnet $^{1}\left(\mathbb{D} \cdot\right.$ Hélène Frankowska $^{1}$}

Published online: 14 September 2021

○) Springer Science+Business Media, LLC, part of Springer Nature 2021

\section{Correction to:}

\section{Applied Mathematics \& Optimization https://doi.org/10.1007/s00245-021-09772-w}

In the original publication of the article, the typesetters inadvertently introduced style, spacing and equation errors in the manuscript.

"The publishers apologise for these errors".

The original article has been updated.

Publisher's Note Springer Nature remains neutral with regard to jurisdictional claims in published maps and institutional affiliations.

The original article can be found online at https://doi.org/10.1007/s00245-021-09772-w.

$凶$ Benoît Bonnet

benoit.bonnet@imj-prg.fr

Hélène Frankowska

helene.frankowska@imj-prg.fr

1 CNRS, IMJ-PRG, UMR 7586, Sorbonne Université, 4 place Jussieu, 75252 Paris, France 